\title{
Digital dialectics: \\ the paradox of cinema in a studio without walls
}

\section{Scott McQuire}

There's a scene in Forrest Gump (Robert Zemeckis, Paramount Pictures; USA, 1994) which encapsulates the novel potential of the digital threshold. The scene itself is nothing spectacular. It involves neither exploding spaceships, marauding dinosaurs, nor even the apocalyptic destruction of a postmodern cityscape. Rather, it depends entirely on what has been made invisible within the image.

The scene, in which actor Gary Sinise is shown in hospital after having his legs blown off in battle, is noteworthy partly because of the way that director Robert Zemeckis handles it. Sinise has been clearly established as a full-bodied character in earlier scenes. When we first see him in hospital, he is seated on a bed with the stumps of his legs resting at its edge. The assumption made by most spectators, whether consciously or unconsciously, is that the shot is tricked up; that Sinise's legs are hidden beneath the bed, concealed by a hole cut through the mattress. This would follow a long line of film practice in faking amputations, inaugurated by the famous stop-motion beheading in the Edison Company's Death of Mary Queen of Scots (aka The Execution of Mary Stuart, Thomas A. Edison, USA; 1895).

By positioning Sinise on the bed, Zemeckis pays lip service to these traditions which depended upon a combination of physical and filmic manipulation. However, in the next shot he completely subverts them, and confounds the expectations of audiences schooled in these values. A single continuous shot shows Sinise being lifted right off the bed, revealing no hole underneath and apparently - no legs. Visual effects supervisor Ken Ralston (from George Lucas' Industrial Light and Magic) commented: 
Gary looked like he had no legs because we eliminated them. We had Gary wear bluescreen stockings over his feet and lower legs that tucked into the ends of his pants. We did blank plate passes of each location to add back to the information Gary's lower legs blocked. After we removed his lower legs, we did some 3-D work and added shadows to make the ends of his legs blend organically into the scene.

Even just a few years after its realisation, what is most significant about such a shot is not its uniqueness but its ubiquity. The fact that effects of this type can be achieved more or less 'seamlessly' without significantly compromising the quality of the image has become central to film making in the 1990s and beyond. This threshold raises a number of points. The first, which is worth making only because it is often overlooked, is that digital technology is not the sole province of sci-fi action films. Forrest Gump is a case in point: apart from the rather unconvincing vignettes which mix Hanks' character with documentary footage of various US Presidents, it is not immediately obvious which scenes are digitally enhanced. Yet, from the swirling feather which lands in Gump's lap at the film's opening to the massive crowd at the antiwar rally in Washington and the entire stadium of the table tennis tournament in China including a virtual ball hit at superhuman speed - the film utilises a significant amount of CGI (computer generated imagery). This recognition that many digital effects, such as wire removal and location dressing, are invisible needs to be extended to acknowledge the fact that, arguably, the biggest impact of digital technology on film making has not been in the realm of CGI, but in sound recording, sound production and picture editing. The relative lack of popular and critical attention to these aspects, compared to the saturation coverage of CGI in films such as Jurassic Park (Steven Spielberg, Universal Pictures; USA, 1993), underlines the pervasive visual bias of most film theory. ${ }^{1}$

Zemeckis' approach in the scene described above foregrounds the potential to use digital technology to subvert audience expectations. Whether this kind of self-conscious play is merely a passing postmodern phase, or part of a more enduring sensibility is a difficult to determine at this moment. And, in industry dominated by the fiction film, it would be naive to understand such a change simply in terms of the faithful celluloid image giving way to the fakery of the computer screen. The history of cinema reveals a complex set of relationships to concepts such as truth and realism, categories which themselves display a fluid correspondence to cinematic genres such as documentary and fiction.

However, the critical point remains that digital technology is rapidly altering the parameters within which narrative conviction and believability will be negotiated in the future. And, while cinema could well be defined as a medium for which technological change is the norm rather than the exception, the current transformations are arguably occurring at a fundamental level. To my mind, the only previous break of comparable scope was the introduction of synchronised sound from around 1927, a shift which cut right across the industry, simultaneously affecting production methods, narrative style and audience experience. With this context in mind, I want to present a 
brief history of the impact of digital technology on cinema, concentrating primarily (but not exclusively) on the experience in Australia. My aim is firstly to examine how changes in technology are affecting contemporary film production (an area which has never been a primary concern of film theory), and then to extend this analysis to consider the implications of such changes for contemporary film theory.

\section{Removing the cotton wool}

The area of film production in which digital technology has been most widely adopted, arguably with the least painful transition, has been sound. Almost all sound recording and processing for Australian feature films now takes place in the digital domain, using DAT (Digital Audio Tape) machines and digital workstations. This constitutes a major change in less than a decade. ${ }^{2}$ What has driven this transition is the ability of the new systems to simplify previously laborious manual tasks. Renowned sound mixer Roger Savage (Return of the Jedi, Shine, Romeo + Juliet) ${ }^{3}$ argues:

The main advantages in digital are the quality control, the speed and the flexibility. The flexibility being that, if all your sound is on a digital workstation, or a series of them, the director can make changes much quicker than if it's on a linear system. That's the biggest thing. ${ }^{4}$

Digital components such as DAT recorders and workstations are far more compact than their analogue counterparts. Instead of roomfuls of tape reels each holding ten-minutes of sound, which need to be physically manipulated throughout the editing and mixing process, the whole process can often be realised on a single unit. There is no need for a separate transfer bay, and, since digital processing simply involves the manipulation of electronic data, there is no risk of degrading original recordings by repeating processing. Digital workstations enable sounds to be catalogued and accessed in a fraction of a second (eliminating tape wind), and, unlike sprocket-based sound editing, all the tracks which have been laid can be immediately heard in playback together. These are powerful advantages. Independent film producer David Elfick (Newsfront, Blackrock) ${ }^{5}$ comments:

I've got to say that there is absolutely no question in my mind that as far as the revolution in sound editing is concerned, there are enormous advantages and no disadvantages whatsoever. It's just so much better and quicker, allowing the creative tools to be there at your fingertips. ${ }^{6}$

This is not to say that there have been no concerns about digital sound. Sound editor Annabelle Sheehan (The Portrait of a $\mathrm{Lady}^{7}$ ) recounts:

The interesting thing people used to do at the beginning was take out Nagras and DATs. People were scared about DATs going over, or cracking up. There was also that thing about Nagras having a creamier sound. ${ }^{8}$

While arguments about the 'warmth' of digital recording remain unresolved, other concerns as to reliability, precision and user friendliness have been largely overcome. Discussing the purpose built digital workstation that his company introduced in 1992 (first used on Strictly Ballroom ${ }^{9}$ ), Roger Savage notes: 
At the time we built the EDI-Tracker there was much more fear of computers from people who weren't computer literate. They did fight the system. There was a certain amount of resistance from some people not wanting to let go of their synchroniser. They felt they couldn't handle this sort of technology. But I think that fear is over now.

One reason that the adoption of digital technology in sound recording and processing has been relatively smooth is the fact that digital systems were, in many respects, merely the practical realisation of a sound revolution which began with the introduction of Dolby Stereo in 1975. Dolby Stereo, which allowed the provision of four tracks of sound on a single optical strip alongside the film image, led to a new generation of experimentation in films such as Star Wars (George Lucas, 20th Century Fox/LucasFilm; USA, 1977). Roger Savage recalls: 'Prior to that, film sound hadn't changed for probably 30 years. It was Mono Academy. ... Star Wars was one of the first films that I can remember where people started coming out of the theatre talking about the sound track'.

Combined with the increasing use of multi-track studio systems for mixing and laying tracks, and the development of new speaker configurations in theatres (including proprietary systems such as LucasFilm's THX), sound in the 1980s became integral to a new type of cinematic experience. Narrative sound events, such as dialogue and music were still concentrated in the front speakers. But the surround sound speakers - available since the introduction of widescreen formats in the 1950s but rarely utilised - became the channels for a new range of spectacular sound effects. In particular, greater emphasis was placed on boosting low frequency response, explicitly mirroring the ambience of amplified rock concerts. Dolby Stereo also enabled the increased 'spatialisation' of sound elements within the theatrical space. These developments present a significant challenge to one of the fundamental presumptions of classical Hollywood narrative: the unity of sound and image, and the subservience of sound to narrative. In a perceptive historical analysis, Rich Altman has argued:

\footnotetext{
Whereas Thirties film practice fostered unconscious visual and psychological spectator identification with characters who appear as a perfect amalgam of image and sound, the Eighties ushered in a new kind of visceral identification, dependent on the sound system's overt ability, through bone-rattling bass and unexpected surround effects, to cause spectators to vibrate - quite literally - with the entire narrative space. It is thus no longer the eyes, the ears and the brain that alone initiate identification and maintain contact with a sonic source; instead, it is the whole body that establishes a relationship, marching to the beat of a different woofer. Where sound was once hidden behind the image in order to allow more complete identification with the image, now the sound source is flaunted, fostering a separate sonic identification contesting the limited rational draw of the image and its characters. ${ }^{10}$
}

In many respects, digital sound systems are extensions of this trajectory. ${ }^{11}$ Perhaps the most marked advantage is improved stereo separation and frequency response which leads to better music reproduction in the theatre. This shift in sound technology goes hand in hand with the 
increased prominence that music and soundtracks have assumed in promoting and marketing films in recent years. Faced with the home video explosion in the 1980s, sound played a critical role in differentiating the cinema experience from domestic viewing. The current spread of digital auditoriums constitutes another phase in this process. Case argues that, at least up to this point, sound has been the most important 'revolution' in contemporary cinema:

I am more and more convinced that the big story about film technology as far as audiences are concerned in the past few years has been sound. Because, although you can do fancy digital things, the image remains glued to that bit of screen in front of your eyes, and it's not really any bigger. ... But the sound has gone from one woolly sound coming from the back of the screen with virtually no frequently range or dynamic range whatsoever. It sounded like a telephone conversation in cotton wool. That was 20 years ago. It has gone from that to something that fills the theatre in every direction with infinitely more dynamic range and frequency range. To me, that's an explosion in the experience compared to what you are seeing on the screen. ${ }^{12}$

\section{Back to the future: non-linear editing}

Digital picture editing on non-linear systems such as Avid or Lightworks has rapidly become an industry standard for feature film production in Australia. However, the adoption of digital technology for picture editing proved more problematic than was the case with sound. This is best understood in historical context. The first moves away from traditional sprocket based editing were signalled as early as 1972, when the Rank Flying Spot Scanner introduced the possibility of finishing films on video. ${ }^{13}$ But, while video opened the door to a new range of cheap, instantly viewable visual effects, the linear nature of tapes proved a headache for editors schooled in film. Non-linear systems, such as LucasArt's EditDroid and Pacific Media's Laser Edit began to appear in the early 1980s. The first digital non-linear systems appeared around the same time, but were hampered by poor image quality, particularly their inability to provide editors with sufficient resolution to achieve accurate lip-synchs. ${ }^{14}$ However, in 1989, the introduction of the Mac-based Avid Media Composer Series revolutionised non-linear editing, and today there are very few Australian feature films not edited on non-linear systems. In a paper presented at the 1994 SMPTE Conference, Dominic Case argued:

Non-linear editing has been adopted in the film and video industry faster than any comparable innovation, and I believe that it has had a greater effect on production and post-production methods even than the introduction of video. ${ }^{15}$

The reason for this rapid acceptance echoes the experience with sound: by reducing the material labour involved in editing, digital systems create greater potential for experimentation. In some respects, the random access allowed by non-linear systems simply restored the situation which prevailed before the introduction of video, since there is no need to rewind or fast forward tapes to locate edit points. However, there are new advantages, most notably the fact that the edited text can be easily altered without the need to physically alter the existing cut. (A common analogy is the impact of word processing on text editing.) Leading editor Nicholas Beauman (Oscar and Lucinda ${ }^{16}$ ) comments: 
When you do a cut on film, it requires you to think about how you are actually going to construct a scene a lot more carefully than if you are cutting on a digital, non linear system. I can throw something together on non-linear very quickly and then look at it and think 'well, no, that's not right'. I can just make a copy of that, or I can put that cut aside do another one and another one. And I can show them all to somebody else. You can't do that on film. Because of the time constraints, you have to think about it very carefully and say 'OK, I am going to go down that road, I think this is the way to go with this scene' If it doesn't work, you have to peel all those splices apart again and start all over, and very few films can afford to do that. ${ }^{17}$

As non-linear editing systems have begun to incorporate additional post-production options such as dissolves, flips, fades and freezes, as well as the ability to lay sound tracks, the nature of the editor's work has changed. Beauman notes:

I would say that in the old days when I cut on film, ninety five per cent of my time was involved in actual picture cutting. Now, cutting on these systems, I would say that at least a third of my time goes into what I do with the sound, what I personally do with the sound. I lay effects in, lay atmospheres, I lay music and the system is so adaptable. In the old days when I cut on film, I might be constantly saying to the director 'look this isn't quite working here but if we have a door slam there, that will make that cut work'. Now I can demonstrate that, I can actually do it, and I can do fades and ramp up music and ramp it down and dip it down under dialogue and make a really smooth presentation with both picture and sound.

These changes offer significant benefits to film makers. Recalling his experience on Blackrock, David Elfick comments:

$[\mathrm{T}]$ he advantage is that, one week into your post-production, when you first look at your picture, you are going to look at it with four tracks of sound. Now to lay up of four tracks of sound at that early stage would be just financially impossible if you were doing it on sprockets, particularly as that lay up would be useless once you start trimming everything.

However, there were a number of problems associated with the introduction of digital editing in Australia. Because digital systems were (and are) considerably more expensive than those they replaced, they were initially promoted to the industry as reducing both edit time and the number of assistants needed. Beauman notes: 'A lot of those things are true. Yes, you can cut a lot faster and make changes more quickly. But you can only think so fast, and it still requires thought'.

Another cost-saving technique promoted in Australia was the practice of cutting the negative directly from the non-linear edit, thus eliminating the cost of making a work print. However, as Dominic Case points out, the practice of viewing film rushes on video screens reduced quality control over the end product:

At the front end, cinematographers weren't seeing their work in the format or the medium they were shooting it on and it was finally being exhibited in. Cinematographers weren't seeing it and editors weren't seeing it, so nobody was seeing if a shot was just marginally out of focus. Sometimes nobody was seeing that character just hovering in the shadows because the shadows are black on the digital screen. And the character turns out to be part of the sound crew who shouldn't be there at all. These are real instances in major features films where this happens. ${ }^{18}$ 
As far as the Australian feature film industry is concerned, my research suggests that these were largely teething problems. Non-linear editing is no longer treated primarily as a cost-cutting alternative, but as a means of achieving a better end result by enabling more thorough exploration of the available material. There has also been a move back in favour of work prints, or at least doing a pos conform (work printing just the takes that the editor has used). ${ }^{19}$

While it is risky to generalise as to the influence of the new technology on editing styles there are some indications. Since digital systems don't discriminate between different image sources, directors such as Baz Luhrmann and Oliver Stone have incorporated a range of formats, including video Hi-8 and Super 8 film, in feature films such as Romeo + Juliet and Natural Born Killers ${ }^{20}$. Non-linear systems also lend themselves to more elaborate edits, and enable an increasing reliance on the 'creation' of shots in the editing process. Editor Jill Bilcock (Romeo + Juliet) comments:

Romeo and Juliet was such a big post-production job it wouldn't have been able to be done in the time on film. So non-linear suited it. Romeo Juliet is definitely a good example of it, because of the reuse of material, the constant slowing down, speeding up, the elaborate stretching of what's there, to pull something into line in the quickest possible way.... [A] lot of the footage didn't exist, so I recreated it through reuse and reworking the material that is already there. You can quickly see those results on the non-linear system, where if you were doing it on film, you would probably have to put in a request for extra money to get interpos and create a film optical. You just wouldn't get it done. It takes a lot more time to do. ... You tend to be a lot more careful about film opticals because of the expense. Now, because you are literally looking at them on a TV monitor, you can look at the whole film overall, you can add titles, you put in dissolves, you can reverse something, you can speed it up. .... You wouldn't cut like that on film. If I was cutting on film, I would be looking for two frames off the floor, I'd be scrounging around. It just wouldn't have that creative freedom. So, creatively, it's really good. ${ }^{21}$

\section{Painting with the camera}

Compared to changes in sound production and picture editing, digital manipulation of the film image has received massive publicity. Undoubtedly, this is partly studio hype to attract audiences, but it also reveals the extent to which computers now have the capacity to redefine cinematic experience. John Colette (Head of Multi-media at the AFTRS) argues:

I think you have to distinguish between things like Avids, or digital sound editing systems, and totally new digital processes. Essentially, an Avid is a Steenbeck, it just works digitally. It does operate with great efficiency, just like a word-processor. ... But compositing tools and modelling tools, rendering and 3-D animation tools, those things are new. ${ }^{22}$

When we can see Sam Neil run from a herd of dinosaurs (Jurassic Park) - in other words when we can see cinematic images of things that we know don't exist - we have to acknowledge that the notion of photorealism and its relation to cinematic spectacle is rapidly changing. While it is far too simplistic to assert that photographs or film images ever granted unmediated access to reality, there has historically been an intimacy between camera images and the objects they represent which has been unmatched by any other medium. ${ }^{23}$ It is this referential bond which has 
come under renewed pressure in the digital era. However, while literature on the impact of digital photography has been multiplying for over a decade, its assumptions are not directly transferable to cinema. In particular, it is necessary to take into account the different status the cine-image assumed when narrative film became the primary form of production and consumption. As film graduated from single shot 'theatrical' texts to more complex narratives built around multi-shot scenes, the direct referential bond frequently posited between image and reality became more complicated. 'Cheating' with the order of events, or the times and locations in which they occur, has long been second nature to film makers. Stop-motion cinematography was the first of an arsenal of 'special effects' used by directors such as George Méliès to manipulate real appearances to fantastic ends.

As writers such as Tom Gunning and Miriam Hansen have stressed, the emergence of new textual conventions was pivotal to cinema's journey from fairground novelty in the 1890s to the picture palaces of the 1920s. By this time, a new logic of montage, shot matching and continuity had become increasingly routinised, with the most influential paradigm coalescing into the model often dubbed 'classical Hollywood narrative'. Once 'realism' was relocated to the structure of the text and the organisation of the viewing experience, it no longer mattered whether or not individual shots had a direct referential relationship to events occurring in a determinate time and place. Cinematic credibility belonged to the movement of the text rather than to the photographic moment - a shift Jean-Louis Commolli has aptly described in terms of a movement from optical to psychological realism. ${ }^{24}$

Walter Benjamin was one of the first theorists to comprehend the significance of this shift. Writing in the 1930s, Benjamin argued that a 'second degree' realism was emerging:

In the theatre one is well aware of the place from which the play cannot be immediately detected as illusionary. There is no such place for the movie scene being shot. Its illusionary nature is that of the second degree, the result of editing. That is to say, in the studio the mechanical equipment has penetrated so deeply into reality that its pure aspect, freed from the foreign substance of equipment, is the result of a special procedure, namely, shooting from a particular camera set-up and linking the shot with other similar ones. The equipment-free aspect of reality has become the height of artifice; the sight of immediate reality has become the 'blue flower' in the land of technology'. ${ }^{25}$

Since the mid-1970s, most film theory has followed Benjamin's lead, eschewing analysis predicated on correspondence between image and object to analysing the structure of the viewing experience. ${ }^{26}$ Within such a paradigm, narrative credibility is no longer determined by the photorealism of individual shots, but also depends upon the film respecting certain conventions linking plot and character to the organisation of space, time and point of view (hence the importance of the psychoanalytic concept of suture for understanding the dynamics of identification in narrative cinema. $\left.{ }^{27}\right)$. 
How does the digital threshold impact on this situation? The growing sophistication of digital image manipulation promises to transform not only the aesthetics of the image, but also its epistemology. As French film maker Jean-Jacques Annaud puts it:

[T]he cinema was built around an animated picture. It has the option of becoming an animated painting. ${ }^{28}$

The malleability of the digital image, and the fact that computer generated elements can now be composited seamlessly at film resolution, alters what has previously been a founding assumption of film theory: that the camera image depicts what a viewer would have seen if looking from the same place at the same time. ${ }^{29}$ Arguably, this shift is of similar moment to the one which took place earlier in this century, as filmic credibility broke from a purely optical realism to occupy the more complex narrative terrain it has since occupied. But, paradoxically, the digital threshold in many respects restores the importance of what Stephen Prince has dubbed 'perceptual realism' in individual shots. Prince argues:

\footnotetext{
A perceptually realistic image is one which structurally corresponds to the viewer's audio-visual experience of three-dimensional space. .... Such images display a nested hierarchy of cues which organise the display of light, colour, texture, movement and sound in ways that correspond to the viewer's own understanding of these phenomena in daily life. Perceptual realism, therefore, designates a relationship between the image on film and the spectator, and it can encompass both unreal images and those which are referentially realistic. Because of this, unreal images may be referentially fictional but perceptually realistic. ${ }^{30}$
}

One of the most significant effects of the increasing use of CGI in film making is the emergence of a new standard for judging the credibility of the film image. The dominant frame for computer artists working in cinema is not simply to create high resolution images, but to make these images look as if they might have been filmed. This includes adding various 'defects', such as film grain lens flare, motion blur and edge halation. As Peter Webb (one of the developers of Flame software) notes:

Flame has a lot of tools that introduce the flaws that one is trained to see. Even though we don't notice them, there is lens flare and motion blur, and the depth of field things, and, if you don't see them, you begin to get suspicious about a shot. ${ }^{31}$

In other words, because audiences have now internalised the camera's qualities as the hallmark of credibility, contemporary cinema no longer aims to mime 'reality', but 'camera-reality'. Such a shift underlines the heightened ambivalence of realism in the digital domain. The film maker's ability to take the image apart at ever more minute levels is counterpointed by the spectator's desire to comprehend the resulting image as 'realistic' - or, at least, equivalent to other cineimages. In some respects, this resembles the dialectic which underlay the earlier development of montage, as a more abstract relation to individual shots became the basis for their reconstitution as an 'organic' text. But instead of the fragmentation and re-assemblage of the image track over time, which founded the development of narrative cinema and its core 'grammatical' structures 
such as shot/reverse shot editing, digital technology introduces a new type of montage: montage within the frame whose prototype is the real time mutation of morphing. ${ }^{32}$

$*$

This is such a far cry from initial experiments with 'computer graphics' - once the arcane preserve of minimalist artists - that it is worth tracing some of the steps in between. ${ }^{33}$ The use of CGI in feature films was initially restricted to title sequences. The next step was to generate images for shots of computer screens, such as that of the ship's computer in Alien (Ridley Scott, 20th Century Fox; USA, 1979). A far more ambitious attempt to marry live action with CGI was undertaken in TRON (Steven Lisberger, Walt Disney Productions; USA, 1982), albeit within the narrative context of a character entering 'cyberspace'. The Last Starfighter (Nick Castle, Universal Pictures; USA, 1984) claims the dubious distinction of having introduced the first CGI space ship. However, neither TRON nor The Last Starfighter proved a box-office success, and the initial wave of enthusiasm for computers in film-making waned. As one analyst put it: 'The problem was that digital technology was both comparatively slow and prohibitively expensive. In fact, work stations capable of performing at film resolution were driven by Cray supercomputers. ${ }^{34}$

Yet, as the computer industry boomed throughout the 1980s, computer-driven special effects became faster, cheaper and more sophisticated, yielding, according to one analyst, 'an entirely different product'. ${ }^{35}$ Who Framed Roger Rabbit? (Robert Zemeckis, Touchstone Pictures; USA, 1988) broke new ground combining computer animation with live action, while James Cameron's Terminator 2: Judgement Day (James Cameron, Tristar Pictures, USA, 1991), featuring the 'liquid metal' T-1000 robot, made morphing a household word. Cameron recounts:

It took a leap of faith - and a greater leap of faith on $T-2$ than on The Abyss ${ }^{36}$, because on The Abyss the computer was really used to solve single sequences, and if that sequence had failed the film still would have succeeded dramatically. On $T-2$ the success or failure of the film was really predicated on the success or failure of the digital techniques. The great leap of faith is that we were ready, or could risk a US\$90 million plus negative - which is a pretty high investment - on a group of people at ILM [Industrial Light and Magic]who couldn't guarantee they could do what I wanted them to but said, 'We're think we're ready'. ${ }^{37}$

This was followed by the massive commercial success of Jurassic Park (1993) which fully legitimated the use of CGI in film. In some respects, the impact of Jurassic Park can be compared to The Birth of a Nation (D.W Griffith, David W. Griffith Corp./Epoch Producing Corporation; USA, 1915). Birth not only catalysed significant changes in film as a narrative medium by incorporating a range of earlier experiments into a feature film, but also transformed cinema as a business enterprise. Its massive profits attracted Wall Street capital to the fledgling US film industry, laying the basis for the vertical integration of production, distribution and exhibition which was critical to the Hollywood studio system. Despite some significant modifications to this model, Hollywood and its currency of spectacle has remained the dominant 
force in world cinema ever since. While the effect of Jurassic Park has not been as far reaching, it nevertheless marked an historic threshold in the relation between cinema and computer. The ability to successfully model, render, animate and composite 3-D images at film resolution, coupled to proven success in recouping the massive investment involved, meant the question was no longer whether or not computers could be successfully used in film making, but how fast would it happen? Steve Williams (senior animator on Jurassic Park) argued in 1993:

In 10 years, the term computer graphics will disappear, because the computer will affect every facet of production. $^{38}$

The subsequent rash of CGI driven blockbusters culminating in the billion dollar plus world-wide gross of Titanic (James Cameron, 20th Century Fox; USA, 1997) has only confirmed this trajectory. And, considered simply in terms of what can be shown in a film quality image, many of the early limitations of CGI, such as compositing new elements into hand-held shots, or replicating the look of hair or water, have now been largely overcome. As James Cameron has remarked, 'Anything is possible right now, if you throw enough money at it, or enough time'.39

Nevertheless, comments of this ilk still need to be taken with a grain of salt. Not only is there always a gap between desire and realisation, but 'realism', whether achieved via camera or computer, is a notoriously slippery goal. Commenting on his path breaking CGI for Jurassic Park, Denis Muren stated: 'Maybe we'll look back in 10 years and notice that we left things out that we didn't know needed to be there until we developed the next version of this technology'. ${ }^{40}$ Muren adds:

In the Star Wars films you saw lots of X-wings fighters blow up, but these were always little models shot with high-speed cameras. You've never seen a real X-wing blow up, but by using CGI, you might just suddenly see what looks like a full-sized X-wing explode. It would be all fake of course, but you'd see the structure inside tearing apart, the physics of this piece blowing off that piece. Then you might look back at Star Wars and say, 'That looks terrible'. ${ }^{41}$

Clearly, George Lucas shared this sentiment, acknowledging in 1997 that 'I'm still bugged by things I couldn't do or couldn't get right, and now I can fix them'. ${ }^{42}$ The box-office success of the digitally enhanced Star Wars trilogy (the re-issued films have grossed over \$200 in the USA alone after Lucas reportedly spent $\$ 15$ million on digital enhancement and $\$ 20$ million on promotion) raises the prospect of a future in which blockbuster movies are perpetually updated with new generations of special effects.

\section{The digital backlot}

Does this mean that movies can now be made entirely in the computer? While the technical answer is yes, perhaps the more penetrating answer is to ask: why would you want to? It is worth remembering that, while Jurassic Park set new standards for CGI, there was only about five to six minutes of computer animation in the whole film. Initially, CGI was intended to be used simply to 
add blur to the Go-Motion puppetry, and even the final animated sequences depended on close collaboration between the model makers and computer animators. For the film makers, the advantage of CGI over models and puppetry was not cost, but flexibility. As Jim Morris (president of Lucas' Industrial Light and Magic) has observed: 'In CG, there aren't really any physical limitations. There are only believability issues .... ${ }^{43}$ Stephen Prince makes a similar point:

Spielberg's dinosaurs made such a huge impact on viewers in part because they seemed far more lifer-like than the miniature models and stop-motion animation of previous generations of film. ${ }^{44}$

As CGI offers film makers visual possibilities that have previously been unattainable, many traditional film making processes and departments, from model making to props, make-up and optical effects are under new threat.. One of the primary casualties of CGI is likely to be the sort of stop-motion puppetry pioneered by Willis O'Brien in The Lost World (Harry Hoyt, First National Pictures; USA, 1925) and King Kong (Merian Cooper \& Ernest Schoedsack, RKO Radio Pictures; USA, 1933), and taken up by his protege Ray Harryhausen in films such as Mighty Joe Young (Ernest Schoedsack, Argory/RKO Radio Pictures; USA, 1949). (Interestingly, Harryhausen was one of the few outsiders asked to preview footage of Jurassic Park, and while impressed, he also criticised its overriding emphasis on 'realism': 'In spite of the jiggling hair and somewhat jerky motion, King Kong has something that a fantasy film needs, and which it loses if you make a film too realistic: an element of dream quality. ${ }^{45}$ ) Even though models may well disappear in the future, it needs to be pointed out that 'state of the art' films such as The Fifth Element (Luc Besson, Columbia Pictures/Gaumont; France/USA, 1997) and Dark City (Alex Proyas, 20th Century Fox; Australia, 1998), still use CGI in conjunction with models and miniatures.

Under similar threat to model making is the area of traditional optical effects, which is being overtaken by more flexible processes. Discussing the path-breaking effects he designed for 2001 : A Space Odyssey (Stanley Kubrick, MGM; UK/ USA, 1968), Doug Trumbull recalls: 'There were scenes in 2001 that were held in the freezer for over a year, waiting for the matte paintings to be filmed. ... Now you can do most of that in a computer with CGI and output to film' ${ }^{46}$ Optical printers were cumbersome for complex processes: if an effect required 40 passes (as some images in the original Star Wars did) and you made a mistake on the 20th, you had to begin all over again. By contrast, since digital compositing is virtually transparent, the limitations to laying new elements into the image are no longer primarily physical, but conceptual and financial.

Richard Edlund (who has won three Academy Awards for his effects work on the Star Wars films) argues:

Now that we have the ability to digitally manipulate images, the whole optical process is upside-down and essentially on the verge of being obsolete. There are still certain esoteric uses for it that are part of the process, so we haven't sold the printers for scrap metal yet. But with the old analog process, everything was a series of fudges - overexposing the matte to get it dense enough and then underdeveloping it, shrinking it 
and adding another matte to give the proper edge quality, or creating subtle motion-control matte fits over a $1 / 2000$ th of an inch range over a hundred frames. It's really pretty bizarre the levels we had to go through to get a convincing shot on the screen. There was also the photochemical process - a monster we had to wrestle to the ground and hold there until we got three slaps from the referee. Now that we have the ability to take each of those 24 frames per second and break them down to pixels, where we have absolute control of the image, it's very exciting. ${ }^{47}$

Digital effects are increasingly being touted as an all-purpose post-production toolkit, capable of fixing anything from a scratch on the film negative to an unwanted pimple on an actor's face. Location dressing is another common application: instead of having to remove TV aerials and advertising signs in order to periodise a streetscape, this can often be done more economically in post-production. ${ }^{48}$ Wire removal is another popular use. Films such as Hook (Steven Spielberg, Tristar Pictures/Columbia/Amblin Entertainment; USA, 1991), Meteor Man (Robert Townsend, MGM/Tinsel Townsend; USA, 1993) and Cliffhanger (Renny Harlin, Boss Film Studios/Caroloc Pictures/Canal +/Pioneer/RCS Video; USA, 1993) have all exploited the new freedom for filming the human body flying or in stunt sequences when scenes can be lit purely for dramatic effect rather than to minimise the visibility of safety harnesses and wire restraints.

But while digital processing is undoubtedly attractive, it comes at a cost. Visual effects cinematographer Steve Newman $\left(B a b e^{49}\right)$ sounds a note of caution:

People think, 'Oh yeah, just put it in the computer, take the wires out, that's brilliant'. But, to do that, you have to scan the film in at $\$ 3$ to $\$ 5$ a frame, and output it back onto film at the end. That's a very expensive way to do something that maybe you could do some other way. ${ }^{50}$

Outside the area of high budget film making, cost remains the major obstacle to the take-up of the new technology. Currently, the digital pathway for standard optical processes such as dissolves is more expensive than traditional lab-based work. Chris Noonan (writer/director of Babe) argues:

[F]or my money at the moment, film still remains the most flexible and cheapest way of going. If digital starts competing with film on cost, then you have good reason to start looking at going that way. ${ }^{51}$

This suggests that even film industries which predominantly make medium and low budget films (as is the case in Australia) need to make a conceptual shift. Instead of treating digital technology as the sole province of high budget action films, it needs to be seen as an alternative production pathway which may be attractive in particular situations, for reasons of flexibility, time saving, or cost.

A major reason is that, in line with general trends in computing, the cost of the digital pathway is coming down all the time. The comparison in some areas is stark. Whereas the average costs of special effects shots on the original Star Wars was around \$50 000, one analyst recently put the average cost at around $\$ 10000$ with the prediction that digital effects would fall as low as $\$ 2000$ in the future. ${ }^{52}$ Such a trajectory is undoubtedly exciting to many low budget and independent film makers. However, as Jim Morris (President of Lucas Digital, the parent company of ILM) notes: 
'If we did the same shots now as we did in $T-2$, those shots would be cheaper today. The fly in the ointment is that very few directors are trying to do what has already been done'. ${ }^{53}$ While morphing can now be done on PCs, Hollywood has long proved adept at raising the currency of spectacle to compete with low-end producers. When asked about the threat posed by independent computer artists to highly capitalised post-production houses such as Digital Domain (which he helped to found in 1993), James Cameron was sceptical:

If you have the sort of garage-band formula where you can sit there and don't care if it takes two days to render, it's going to reach a point pretty soon where you can do most of what can be done at a high-end facility. But that isn't really going to change the basic paradigm for film making. ... The thing that everybody fails to remember here is that when you're making a big effects film and you've got over 200 shots in the film, you've got issues of management, you've got issues of dealing with the day-to-day flow of the work, and you've got organizational problems. It's a little bit like saying, 'with these tools, I can go out in my backyard and build a car.' Well, yeah, you might be able to build a car, but can you build the Ford Motor Company? Can you build a thousand of them? I don't think so. ${ }^{54}$

Another area in which digital technology is having significant effects is by reconfiguring the established model of film production. Pre-production, production and post-production are now far more likely to overlap than in the past. Digital effects specialist Peter Doyle notes:

What you'll find is that it is becoming much less linear, as in picture cut, picture effects, sound cut, sound effects, final mix, final grade, release. You'll find that all sectors are happening at the same time. It's happening in Sydney, as we speak, on Alex Proyas' film [Dark City]. It's being shot, it's being cut, special effects are happening and sound effects are happening, and it's being test screened, all at the same time. ${ }^{55}$

George Lucas, who has been one of the strongest proponents of digital production, notes similar changes in making Star Wars parts 4-6:

I have been writing it [the next Star Wars episode] for two years, but I've also been shooting and editing, exploring different kinds of actors for different kinds of parts, and shooting and figuring it out. It's not done sequentially at all. ${ }^{56}$

Computer based pre-visualisation is taking on increasing importance, not only in planning complex multi-camera shots, but also in determining which portions of a set can be left undressed or even unbuilt because they will never be in shot. Portable editing suites have been used to digitise footage on location for some productions, as a guarantee that complete coverage of expensive scenes has been achieved. And new communication tools, such as the videofax, have been used to link film crews working in different cities or even different continents. While all these developments towards 'parallel processing' can be seen as logical responses to new technology, they also demand the introduction of new protocols of communication between different film departments. Nowhere is this more evident than with regard to the changing role of the cinematographer. 
Increasingly, cinematographers are being called upon to collaborate with post-production technicians in the construction of composite images in which the pro-filmic action is only one element. Cinematographer Andrew Lesnie (DOP on Babe, 1995) notes:

I think digital technology is redefining the role of cinematography in terms of the authorship of images, more than anything. From some cinematographers there is a certain paranoia about becoming redundant or being made obsolete or having the facility to design and control the mood wrestled away from them. I don't see it that way myself. I've just looked at it as basically another tool that you've got to work with. ${ }^{57}$

Even more emotionally charged is the prospect of 'filmless cinema' - cinema which no longer utilises celluloid film. The economic imperatives in an industry living on the bottom line are selfevident. In the United States alone, the annual cost of release prints is estimated at half a billion dollar. James Cameron argues: 'The second that all you need to do is to pipe terrabytes of data out to a theatre someplace, there's no point in ever seeing film' ${ }^{58}$ Most cinematographers disagree, pointing to the different qualities and properties of the electronic image compared to the chemical grain of film emulsion. George Lucas supports their perspective, but does so in a way which threatens to make it redundant:

They [cinematographers] are correct: it is a different look and it does have different qualities [but] that doesn't make it bad; it just basically makes it different. And eventually, eventually, you will be able to make [the two methods] look the same. We're not there yet, but this is all in its infancy. ... I think eventually you will be creating black and white looks, colour looks and the new digital look. But it will all be done digitally. ${ }^{59}$

To true believers such as Lucas and Cameron, all digital production is unstoppable. Cameron argues that the image quality of high-definition cameras is no longer the major obstacle:

Now the problem is that it's a \$3 million camera and a \$5 million recorder, and the camera weighs about 600 pounds. An Arri $2 \mathrm{C}$ can record an image just as well, but it weighs only 16 pounds and can cost $\$ 20000$, so there's still a big gulf between the two. ${ }^{60}$

Rather than leaping straight into all-digital films, a more likely scenario is a hybrid model which preserves the role of film as an initial capture and final projection medium, but locates all other processing (from sound production and picture editing to effects, titles, colour grading, etc) in the digital domain. Such an outcome could be achieved by the adoption of the new generation of hybrid cameras which record film and digital data simultaneously, or by end to end scanning of the film negative once it has been shot. Putting an entire feature film in the digital domain is currently an incredibly expensive option which remains out of reach of most film makers. But for those at the very high budget end of production, it may come to be regarded as a form of insurance, ensuring that any unforeseen problems can be easily fixed.

Returning to the question of why you would want to create films entirely or even largely in the digital domain, beyond the issue of cost, the most common answer is control. Doug Trumbull comments: 
I think what we're seeing now as a result of the integration of computer graphics, live action and miniatures is the ability to realise a fundamental goal of the entertainment industry from its inception: to stay inside the studio and create any world we can possibly imagine, and do it absolutely seamlessly and photo-realistically in a way that's far superior to any of the old techniques. ${ }^{61}$

\section{George Lucas espouses a similar vision:}

I think cinematographers would love to have ultimate control over the lighting; they'd like to be able to say, 'OK, I want the sun to stop there on the horizon and stay there for about six hours, and I want all of those clouds to go away. Everybody wants that kind of control over the image and the storytelling process. Digital technology is just the ultimate version of that. ${ }^{62}$

Lurking within such a vision are quite radical changes to film making practice. LucasFilm's approach to their production of Radioland Murders (Matthew Robins, LucasFilm; USA, 1994) is instructive. They integrated the filming of green screen sequences with principal photography, and filmed a number of 'off the cuff' shots of the actors to be used for new shots to be created in post. A logical extension is the idea of filming entire performances in front of blue or green screens. Robins (director of Radioland Murders ) comments:

I find it a double edged sword. George loves the idea of coming to work in the morning and going into a big blue box with a couple of actors and a couple of hand props, then put everything else in later. I understand the attraction if you like working that way and sometimes I do, but I don't entirely agree that having all this stuff available later is the ultimate liberation of the imagination. ${ }^{63}$

Could one go further and eliminate live actors altogether? Mark Hamill (Luke Skywalker in the Star Wars films) has remarked: 'I have a sneaking suspicion if there were a way to make movies without actors, George would do it'. ${ }^{64}$ In a digital variant of the experiments conducted by nineteenth century French biologist and photographic pioneer, Etienne-Jules Marey, Mark Dippé (visual effects co-supervisor on Jurassic Park) has proposed putting actors in wired body suits to enable their movements to be precisely recorded. These performances could then be composited into new locations, providing templates for new characters to be 'skinned' onto old gestures. Other variants of this scenario are the digital regeneration of dead actors by compositing their images into new films, or the generation of digital characters which are capable of carrying an entire movie themselves. ${ }^{65}$

How realistic are such developments? As well as the technical and financial difficulties which are far from being resolved, there is the more fundamental question as to the sort of films you want to make. While the digital backlot undoubtedly suits the approach of certain film makers and certain types of film making, there is a huge spectrum of cinema for which location shooting and real actors are irreplaceable. The first all digital productions (following in the wake of Toy Story ${ }^{66}$ ) will undoubtedly have novelty value. But even those working primarily in the digital domain will ignore the craft of acting only at their peril. Australian writer and film maker Ross Gibson argues that good digital animators need more than purely technical skills: 
What I am interested in is how great animators do actually have an actor's sense of body. When I was living in London, I went to a couple of lectures that Chuck Jones gave, and what struck me most of all was his understanding of the performative body, and him talking about how you absolutely have to know how Bugs moves, how he stands in any one of the millions of moments that you've got to produce for him. It always occurred to me that a good animator is more like an actor than a director. ...

Where it gets intriguing is whether it will be understood that traditional actorly training still will be necessary. ... That's the sort of thing that makes me really curious about the future. If I were running a digital editing and animating class in 20 years time, I would actually want people to do one and a half years of actor's training as part of their editor's and animator's training. But I doubt that will happen, just because of the kind of technicist pigeonholing that occurs.

\section{In conclusion}

The digital threshold now offers film makers the prospect of a 'studio without walls', extending the ability to control the cine-image down to the level of the pixel. This capacity to 'paint' with film resolution images is necessarily altering the established boundaries of realism. A comparison to traditional photography is instructive. While photographers inevitably make choices concerning subject matter, framing, lens, film stock, aperture, shutter speed, and so on - all of which affect the resulting image - there is nevertheless a sense in which the image also arrives from beyond the photographer's control. This 'also' is important. While the photograph was never a purely 'objective' medium in the sense given it by nineteenth century positivism, nor was it a 'subjective' creation in the manner of a painting or drawing. Walter Benjamin argued that this hybridity is precisely what attracts us to photography:

No matter how artful the photographer, no matter how carefully posed his subject, the beholder feels an irresistible urge to search such a picture for the tiny spark of contingency, of the Here and Now, with which reality has seared the subject..${ }^{67}$

Because of the popularity of the fiction film, cinema has always been a special case in this scene. Yet, beneath the levels of control exercised by script, props, direction and the like, there is still a degree of contingency that inevitably enters the filmed image - a momentary look on an actor's face, a chance configuration of light and shadow, a random juxtaposition of objects. It is this realm of contingency that the digital threshold overtakes. Will this produce a long term shift in cinema aesthetics? Will it result in more formularised, less unpredictable, more boring productions? Or is this transition better understood as the latest in a long line of arguments over 'realism' and 'formalism' which have dotted the history of cinema? While I find the second perspective persuasive, I suspect that as the truth value long associated with camera images wanes, we may look back on the 1990s (and the response to footage such as that of the Rodney King beating), as the point at which an important cultural-political - and not merely technical threshold was crossed. 
Quoted in Ron Magid 'ILM Breaks New Digital Ground for Gump', American Cinematographer, 75 (10) (1994), p. 47.

${ }^{1}$ Philip Brophy has argued: 'Next to 3-D, sound recording, mixing and presentation are among the most overlooked aspects of film theory and criticism (both modern and postmodern strands)'. 'The Architectsonic Object - Stereo Sound, Cinema and Colours' in Philip Hayward (ed.), Culture, Technology and Creativity in the Twentieth Century (London, 1990), p. 91.

${ }^{2}$ DAT recorders were demonstrated by NHK in Japan as early as 1967 and became commercially available in Japan in 1987. However, it wasn't until the early 1990s that digital sound processing began to be adopted as a production paradigm in Australia.

${ }^{3}$ Return of the Jedi, Richard Marquand, 20th Century Fox/LucasFilm; USA, 1983; Shine, Scott Hicks, Fine Line Features/Momentum Films; Australia, 1996; William Shakespeare's Romeo + Juliet, Baz Luhrmann, 20th Century Fox/Bazmark, USA, 1996.

${ }^{4}$ All quotes from Roger Savage are from an interview with the author conducted in May 1997.

${ }^{5}$ Newsfront, Philip Noyce, Palm Beach Pictures, Australia, 1978; Blackrock, Steven Vidler, Palm Beach Pictures, Australia, 1997.

${ }^{6}$ All quotes from David Elfick are from an interview with the author conducted in March 1997.

${ }^{7}$ The Portrait of a Lady, Jane Campion, Grammercy Pictures/Polygram Filmed Entertainment/Propaganda Films; UK/USA, 1996.

${ }^{8}$ Interview with the author conducted in March 1997.

${ }^{9}$ Strictly Ballroom, Baz Luhrmann, M \& A Film/Rank; Australia, 1992.

${ }^{10}$ Altman, R. 'The Sound of Sound: A Brief History of the Reproduction of Sound in Movie Theatres', Cineaste 21(1/2) (1995) (Supplement: Sound and Music in the Movies)

${ }^{11}$ There are currently three principal systems for digital sound. DTS (Digital Theatre Systems) was developed by Universal Pictures, SDDS (Sony Dynamic Digital Sound) by Sony Columbia and SR D (Dolby Digital) by Dolby. The three systems are incompatible because they use different decoding devices. Roger Savage notes: '[N]ow a lot of the big blockbuster films have got all formats on the one print. Romeo + Juliet, which we did, ended up with SR D, SDDS, and DTS all on the one print, so it could go into any digital house and get played'. ${ }^{12}$ All quotes from Dominic Case are from an interview with the author, March 1997, except where otherwise noted.

${ }^{13}$ See Les Paul Robley, 'Digital Offline Video Editing: Expanding Creative Horizons', American Cinematographer, 74 (4) (1993) p. 55.

${ }^{14}$ See Paul Brown 'Digital Technology and Motion Pictures' in Ross Harley (ed.) New Media Technologies (Sydney, 1993), p. 87.

${ }^{15}$ Dominic Case, 'Converging Technologies and Newton's Third Law of Motion, or: The Close-up, the cutaway and the freeze-frame', reprinted in Cinema Papers, 101 (1994), p. 50.

${ }^{16}$ Oscar and Lucinda, Gillian Armstrong, Dalton Films/Meridian Films/New South Wales Film and Television Office/Australian Film Finance Corporation; Australia/USA, 1997.

${ }^{17}$ When I interviewed him, Beauman was in the process of editing Oscar and Lucinda. He noted: 'We are up to something like version five of the film at the moment now, but in fact its probably like version seven, and there will be at least one other version after this. You just didn't have the time to go through the film that many times when you were cutting on film, and every time you do, you refine, refine, refine'.

${ }^{18}$ Interview with the author, March, 1997.

${ }^{19}$ Case estimated in 1997 that a quarter of feature films were using work prints and another quarter doing a pos conform.

${ }^{20}$ Natural Born Killers, Oliver Stone, Warner Brothers; USA, 1994.

${ }^{21}$ Interview with the author, April 1997.

${ }^{22}$ Interview with the author March 1997.

${ }^{23}$ As I have argued at length elsewhere, at its inception the photographic camera drew together a number of threads to establish its powerful cultural authority over 'realism'. These included the geometric perspective established as the currency of realism in European oil painting since the Renaissance, the intimate association of light vision and truth which has been a staple of western philosophy, and the desire to invest a visual machine with the virtues of scientific objectivity which proved irresistible to nineteenth century positivism. See my Visions of Modernity: Representation, Memory, Time and Space in the Age of the Camera (London, 1998). 24 'Machines of the Visible' in Stephen Heath \& Theresa De Lauretis (eds.) The Cinematic Apparatus, (London, 1980), p. 130.

${ }^{25}$ Walter Benjamin, W. Illuminations (trans. H. Zohn) (London, 1973), pp. 234-235. This translation is modified in accordance with Miriam Hansen's rendering of the passage, which brings out the ambivalent connotations of Benjamin's final reference to 'immediate reality'. See her 'Benjamin, Cinema and Experience: "The Blue Flower in the Land of Technology", New German Critique, 40 (1987) pp. 203-204. 
${ }^{26}$ I am thinking particularly of publications such as Screen, Camera Obscura, Cineaste, Wide Angle and Framework and theorists such as Christian Metz, Raymond Bellour, Jean-Louis Commolli, Stephen Heath, Laura Mulvey, and Constance Penley.

${ }^{27}$ On the concept of suture, see the special 'Dossier on Suture', Screen 18 (4) (1977-78).

${ }^{28}$ Jean-Jacques Annaud 'Digital Future', Sight and Sound, 6(5) (1996), p. 15.

${ }^{29}$ Within conventional constraints of lens type, film stock, shutter speed, focus, optical effects, etc.

${ }^{30}$ Stephen Prince, 'True Lies: Perceptual Realism, Digital Images and Film Theory', Film Quarterly, 49 (3) (1996), p. 32.

${ }^{31}$ Quoted in Dominic Case, 'Flame at Complete Post' Cinema Papers 102 (1994), p. 63. A good example is the description given by compositing supervisor Mike Kanfer of the techniques used for the rocket launch sequence in Apollo 13 (Ron Howard, Universal Pictures; USA, 1995): 'The most challenging aspect of the film was to recreate something real, as if Hollywood was there at the actual launch. We used every trick to create photorealism in the compositing. Our rockets were shot against black, then composited into blue sky backgrounds - usually either entirely fabricated or at least augmented - without black matte lines. Also, we shot the Saturn V with a ProMist filter, which gave us glints of sun off the white sides of the rocket. Once we added all the CG ice, vapor, fire and shake, these shots looked like you were really there. Ultimately every image had all the photographic artifacts of the real event: the glares burn out, there's grain on CG elements and motion blur'.

${ }^{32}$ Developed in 1982, the technique of morphing was arguably the first 'signature' digital visual effect. It involves the detailed mapping of an object in one image onto another so that the transition between shots is far more fluid than a traditional dissolve. It was first used in Hollywood in the feature film Willow (Ron Howard, MGM/LucasFilm; USA, 1988).

${ }^{33}$ For a discussion of the history of computer graphics, see M. King 'Programmed Graphics in Computer Art and Animation', Leonardo, 28 (2) (1995), pp. 113-121.

${ }^{34}$ Brad Fisher, “'Digital Cinematography”: A Phrase of the Future?' (part 1), American Cinematographer, 74 (4) (1993), p. 52.

${ }^{35}$ R. Baker, 'Film Technology and Special Effects in Contemporary Cinema' in Philip Hayward \& Tana Wollen (eds.) Future Visions: New Technologies for the Screen (London 1993), p. 37

${ }^{36}$ The Abyss, James Cameron, Twentieth Century Fox/Lightstorm Entertainment/Pacific Western; USA, 1989.

${ }^{37}$ Paula Parisi, 'Cameron Angle', Wired. 5(04) (1996), p. 133.

${ }^{38}$ Ron Magid, CGI and Special Effects, American Cinematographer, 74 (12) (1993) p. 27.

${ }^{39}$ Paula Parisi, 'Cameron Angle', Wired. 5(04) (1996), p. 133.

${ }^{40}$ Muren quoted in Ron Magid, 'ILM's Digital Dinosaurs Tear Up Effects Jungle', American Cinematographer, 74 (12) (1993), p. 57.

${ }^{41}$ Muren quoted in Ron Magid, 'CGI Spearheads Brave New World of Special Effects', American Cinematographer, 74 (12) (1993), p. 28.

${ }^{42}$ Ron Magid, 'George Lucas: Past, Present and Future', American Cinematographer, 78 (2) (1997), p. 49.

${ }^{43}$ Quoted in John Seabrook 'Why Is The Force Still With Us?', The New Yorker, January 6 (1997), p. 53.

${ }^{44}$ Stephen Prince, 'True Lies: Perceptual Realism, Digital Images and Film Theory', Film Quarterly, 49 (3) (1996), p. 28.

${ }^{45}$ Harryhausen quoted in Ron Magid, 'Exploring the Future of Special Effects', American Cinematographer, 75

(2) (1994), p. 28

${ }^{46}$ Trumbull interviewed by Bob Fisher \& Marji Rhea, American Cinematographer, 75 (8) (1994), p. 60.

${ }^{47}$ Edlund quoted in Ron Magid, 'CGI Spearheads Brave New World of Special Effects', p. 27.

${ }^{48}$ The first production to make extensive use of digital technology in this fashion was George Lucas' teleseries

The Young Indiana Jones Chronicles (30 episodes, various directors; USA' 1992-93), pioneering its broader application in feature film production.

${ }^{49}$ Babe, Chris Noonan, Universal Pictures/Kennedy-Miller Productions; Australia/USA, 1995.

${ }^{50}$ Interview with the author, March, 1997.

${ }^{51}$ Interview with the author April, 1997.

${ }^{52}$ Dale Duguid, 'The Digital Freight Train is Coming', Cinema Papers, 104 (1995), p. 33.

${ }^{53}$ John Seabrook, 'Why Is The Force Still With Us?', The New Yorker, January 6 (1997), p. 53.

${ }^{54}$ 'Cameron Angle', p. 178.

${ }^{55}$ Interview with the author, March 1997.

${ }^{56}$ Kevin Kelly \& Paula Parisi, 'Beyond Star Wars: What's Next For George Lucas', Wired 5(02) (1997).

${ }^{57}$ Interview with the author, March 1997.

${ }^{58}$ Paula Parisi, 'Cameron Angle', Wired. 5(04) (1996), p. 175. 
${ }^{59}$ Ron Magid, 'George Lucas: Past, Present and Future', p. 50. Discussing the Star Wars prequel, Lucas added: 'If it wasn't going to be a widescreen picture, it would definitely be digital. But we're not there yet. ... I think we'll be there in the next eighteen months ...'. (p. 52)

60 'Paula Parisi, 'Cameron Angle', Wired. 5(04) (1996), p. 175.

${ }^{61}$ Quoted in Ron Magid 'CGI Spearheads Brave New World of Special Effects', American Cinematographer, 74 (12) (1993), p. 32.

${ }^{62}$ Ron Magid, 'George Lucas: Past, Present and Future', p. 52.

${ }^{63}$ Ron Magid, 'Finetuning Radioland Murders', American Cinematographer, 76 (3) (1995), p. 72.

${ }^{64}$ John Seabrook 'Why Is The Force Still With Us?', The New Yorker, January 6, 1997, p. 53.

${ }^{65}$ One example of the second tendency is the Synthespian project begun by the Kleiser-Walczak Construction Co. in 1987.

${ }^{66}$ Toy Story, John Lasseter, Walt Disney Productions/Pixar Animation Studios; USA, 1995.

${ }^{67}$ Walter Benjamin One Way Street and Other Writings (trans. E. Jephcott \& K. Shorter) (London, 1979), p. 243. 


\section{University Library}

\section{- M M N E R VA A gateway to Melbourne's research publications}

Minerva Access is the Institutional Repository of The University of Melbourne

Author/s:

MCQUIRE, S.

Title:

Digital dialectics: the paradox of cinema in a studio without walls

Date:

1999

Citation:

McQuire, Dr Scott (1999) Digital dialectics: the paradox of cinema in a studio without walls, in Historical Journal of Film, Radio and Television, 19(3):pp 379-397.

Publication Status:

Published

Persistent Link:

http://hdl.handle.net/11343/34890 